\title{
Thyroid Hormone Increases TGF- $\beta 1$ in Cardiomyocytes Cultures Independently of Angiotensin II Type 1 and Type 2 Receptors
}

\author{
Gabriela Placoná Diniz, ${ }^{1}$ Marcela Sorelli Carneiro-Ramos, ${ }^{2}$ \\ and Maria Luiza Morais Barreto-Chaves ${ }^{1}$ \\ ${ }^{1}$ Laboratory of Cellular Biology and Functional Anatomy, Department of Anatomy, Institute of Biomedical Sciences, \\ University of São Paulo, 05508-900, São Paulo, Brazil \\ ${ }^{2}$ Department of Cell and Developmental Biology, Institute of Biomedical Sciences, University of São Paulo, \\ 05508-900, São Paulo, Brazil
}

Correspondence should be addressed to Maria Luiza Morais Barreto-Chaves,mchaves@usp.br

Received 21 July 2009; Revised 11 February 2010; Accepted 21 March 2010

Academic Editor: Fausto Bogazzi

Copyright (๑) 2010 Gabriela Placoná Diniz et al. This is an open access article distributed under the Creative Commons Attribution License, which permits unrestricted use, distribution, and reproduction in any medium, provided the original work is properly cited.

TH-induced cardiac hypertrophy in vivo is accompanied by increased cardiac Transforming Growth Factor- $\beta 1$ (TGF- $\beta 1$ ) levels, which is mediated by Angiotensin II type 1 receptors (AT1R) and type 2 receptors (AT2R). However, the possible involvement of this factor in TH-induced cardiac hypertrophy is unknown. In this study we evaluated whether TH is able to modulate TGF- $\beta 1$ in isolated cardiac, as well as the possible contribution of AT1R and AT2R in this response. The cardiac fibroblasts treated with $\mathrm{T}_{3}$ did not show alteration on TGF- $\beta 1$ expression. However, cardiomyocytes treated with $\mathrm{T}_{3}$ presented an increase in TGF- $\beta 1$ expression, as well as an increase in protein synthesis. The AT1R blockade prevented the $\mathrm{T}_{3}$-induced cardiomyocyte hypertrophy, while the AT2R blockage attenuated this response. The $\mathrm{T}_{3}$-induced increase on TGF- $\beta 1$ expression in cardiomyocytes was not changed by the use of AT1R and AT2R blockers. These results indicate that Angiotensin II receptors are not implicated in $\mathrm{T}_{3}$-induced increase on TGF- $\beta$ expression and suggest that the trophic effects exerted by $\mathrm{T}_{3}$ on cardiomyocytes are not dependent on the higher TGF- $\beta 1$ levels, since the AT1R and AT2R blockers were able to attenuate the $\mathrm{T}_{3}$-induced cardiomyocyte hypertrophy but were not able to attenuate the increase on TGF- $\beta 1$ levels promoted by $\mathrm{T}_{3}$.

\section{Introduction}

The major causes of morbidity and mortality in Western societies have been associated with cardiac hypertrophy and heart failure, which are influenced by several factors [1, 2]. In this context, the cardiomyocytes are known to play important role in the adaptation of myocardial structure and function during cardiac hypertrophy [3-6]. In this sense, several studies have investigated the effects promoted by hypertrophic stimulus in isolated cardiomyocytes in order to evaluate the complex process that coordinates the cardiac hypertrophy.

Increased thyroid hormone (TH) levels exert important effects on the cardiovascular system, including the induction of cardiac hypertrophy. TH metabolic disarray, as occurs in the hyperthyroidism, has been identified as a high-risk factor for the progression of cardiac diseases and development of heart failure [7]. In addition, $\mathrm{TH}$ has been shown to stimulate growth in cardiomyocytes in vitro and in vivo, through a combination of direct and indirect effects, which lead to increased cell size, protein synthesis, and changes in target genes related to cardiac function [8]. In the last decade, some studies demonstrated that the Renin Angiotensin System (RAS) exerts a critical role to the development of the THinduced cardiac hypertrophy in vivo $[9,10]$ and in vitro [11]. The Angiotensin II (Ang II), one of the main effectors of the RAS, exerts its effects via the Ang II type 1 (AT1R) and type 2 receptors (AT2R). Although most of hypertrophic effects of Ang II are mediated by the AT1R [12], the AT2R has also been implicated in mediating cardiac growth $[13,14]$.

Another important mediator of the cardiac hypertrophy is the Transforming Growth Factor- $\beta 1$ (TGF- $\beta 1)[15,16]$, 
which is present in cardiomyocytes and has been implicated in promoting growth of these cells [17]. In this sense, stimulus that triggers the expression of TGF- $\beta 1$ has been associated with an increase on the Ang II levels in the cardiac tissue [18]. Our group recently demonstrated that $\mathrm{TH}$-induced cardiac hypertrophy is accompanied by elevated Ang II levels in vivo and in vitro [11]. Moreover, we also showed that TH-induced cardiac hypertrophy in vivo is accompanied by an increase of cardiac TGF- $\beta 1$ expression, which occurs in dependence on AT1R and AT2R activation [19]. However, the possible contribution of this factor to the TH-induced cardiac hypertrophy is not known. In the same way, the possible involvement of the higher Ang II levels to the TGF- $\beta 1$ modulation induced by $\mathrm{T}_{3}$ in isolated cardiac cells, as well as the possible contribution of AT1R and AT2R in this response is also unknown yet. Then, considering that TH and RAS influence several hemodynamic factors and that the heart is composed by several cell types, which could be contributing to the participation of the Ang II receptors in the increase on cardiac TGF- $\beta 1$ levels, the aim of the present paper was to investigate whether TH is able to modulate TGF- $\beta 1$ levels in isolated cardiac cells, as well as the possible contribution of AT1R and AT2R in this process. To address these questions, cardiomyocytes and cardiac fibroblasts cultures were treated with $\mathrm{T}_{3}$, simulating a hyperthyroidism condition in vitro. In addition, we used pharmacologic blockers of AT1R and AT2R to evaluate the role of these receptors on TGF- $\beta 1$ levels, as well as in $\mathrm{T}_{3}$ induced cardiomyocyte hypertrophy.

Herein, we showed that the cardiomyocytes treated with $\mathrm{T}_{3}$ presented higher TGF- $\beta 1$ expression levels. In addition, we confirmed that $\mathrm{T}_{3}$ promotes cardiomyocyte hypertrophy in part via AT1R and AT2R. However, the $\mathrm{T}_{3}$-induced increase in TGF- $\beta 1$ expression in cardiomyocytes was not changed by the use of AT1R and AT2R blockers. These results indicate, for the first time, that the local Ang II receptors, present on cardiomyocytes, are not implicated in $\mathrm{T}_{3}$-induced increase in TGF- $\beta$ expression in these cells. In addition, these data suggest that the trophic effects exerted by $\mathrm{T}_{3}$ on cardiomyocytes do not depend on the higher TGF- $\beta 1$ levels, as observed previously for us in vivo, since the AT1R and AT2R blockers were able to attenuate the $\mathrm{T}_{3}$-induced cardiomyocyte hypertrophy but were not able to modulate the increase in TGF- $\beta 1$ levels promoted by $T_{3}$ in these cells.

\section{Material and Methods}

2.1. Cardiac Myocytes and Fibroblasts Cultures. All protocols were performed in accordance with the Ethical Principles in Animal Research set forth by the Brazilian College of Animal Experimentation and were approved by the Biomedical Sciences Institute/USP Ethics Committee for Animal Research. Primary cultures of neonatal rat ventricular cardiomyocytes were prepared by enzymatic disaggregation, as described previously by us in [20]. To segregate myocytes from nonmyocytes, the dissociated cells were layered into discontinuous Percoll (Amersham Biosciences, Sweden) density gradient. The cells were collected and washed to remove all traces of Percoll. Cellular viability was estimated by Trypan blue method. Cardiomyocytes were cultured in Dulbecco's modified Eagle's medium (DMEM, GIBCO) containing 5\% newborn calf serum (NCS; Invitrogen, Carlsbad, CA) and $10 \%$ horse serum (Invitrogen). The cardiac fibroblasts were cultured in DMEM containing 10\% fetal bovine serum (Invitrogen), which in confluence, were submitted subsequently to subculture. Cells from passage 1 through 2 were grown to confluence and then used in the experiments. The cells were maintained in a humidified incubator $\left(5 \% \mathrm{CO}_{2}\right.$, $\left.37^{\circ} \mathrm{C}\right)$.

2.2. Treatment of the Cells. 72 hours after plating, the isolated cardiac cells were maintained in DMEM containing serum $0.5 \%$ for 24 hours. Then, the cardiomyocytes and cardiac fibroblasts cultures were treated with serum-free medium containing $\mathrm{T}_{3}(10 \mathrm{nM}$, Sigma, St. Louis, MO) or only serum-free medium in control cells for 24 hours. To evaluate the possible role of AT1R and AT2R on cardiomyocytes cultures, the cells were treated with serumfree medium containing $\mathrm{T}_{3}(10 \mathrm{nM}), \mathrm{T}_{3}$ plus Losartan (Los, $1 \mu \mathrm{M}$, Sigma Chemical), $\mathrm{T}_{3}$ plus PD123319 (PD, $1 \mu \mathrm{M}$, Sigma Chemical) or only serum-free medium in control cells for 24 hours.

2.3. Protein Synthesis. Protein synthesis on cardiomyocytes cultures was quantified on the basis of tritiated leucine incorporation [21]. Six hours before harvest, L- $\left[3,4,5-{ }^{3} \mathrm{H}\right]$ leucine ( $5 \mu \mathrm{Ci} / \mathrm{ml}$ ) was added to the culture medium to measure incorporation into newly synthesized protein. Total cellular proteins were precipitated in ice-cold $10 \%$ trichloroacetic acid and collected by centrifugation $(14000 \mathrm{Xg}, 10 \mathrm{~min}$, $4^{\circ} \mathrm{C}$ ). The proteins pellets were washed twice by resuspension in cold $10 \%$ trichloroacetic acid and collected by centrifugation. The final pellets were dissolved in $0.2 \mathrm{~N} \mathrm{NaOH}$ by incubation at $60^{\circ} \mathrm{C}$ for $30 \mathrm{~min}$. The radioactivity was measured by liquid scintillation counting and normalized by the total cell number.

2.4. Western Blotting. Protein expression of TGF- $\beta 1$ and $\alpha$ actinin was determined by Western Blotting experiments. Total proteins from cell cultures were obtained using digestion buffer ( $\mathrm{KCl} 90 \mathrm{mM}$, Hepes $10 \mathrm{mM}, \mathrm{MgCl}^{2+} 3 \mathrm{mM}$, EDTA $5 \mathrm{mM}$, glycerol $1 \%$, DTT $1 \mathrm{mM}$, SDS 0.04\%). Protein concentrations were analyzed by the Bradford method (Bradford 1976). One hundred $\mu \mathrm{g}$ of total protein was resolved by electrophoresis on $5 \%$ stacking/ $10 \%$ polyacrylamide-SDS gels, and the resolved proteins were transferred to nitrocellulose membrane (Bio-Rad, CA, USA). The membrane was stained with Ponceau solution to demonstrate that the protein concentration was similar in the different samples. The membrane was then washed with TBST (Tris $50 \mathrm{mM}$, $\mathrm{NaCl} 150 \mathrm{mM}$, pH 7.5 and Tween-20 2\%) for 10 minutes at room temperature. After this, the membrane was incubated at $4^{\circ} \mathrm{C}$ overnight with polyclonal antibody against TGF- $\beta 1$ (Santa Cruz Biotechnology, CA, USA, SC-146, 1:500) and $\alpha$-actinin (Santa Cruz Biotechnology, SC-15335, $1: 1000$ ) in 
TBST. After washing the membrane, the secondary antirabbit or antigoat I gG antibody conjugated with peroxidase (Amersham Biosciences, New Jersey, USA) at a 1:10000 dilution in TBST was added for 1 hour at room temperature. The membrane was washed again with TBST and was incubated with ECL detection reagents (Amersham Biosciences), which produced a chemiluminescence signal that was detected by exposure to X-ray film. The protein bands were quantified by densitometry and the band density was then calculated. The TGF- $\beta 1$ protein expression was normalized by $\alpha$-actinin expression. The values are expressed in percentage in relation to control.

2.5. Gene Expression Analysis. Total RNA from cardiomyocytes and fibroblasts cultures were isolated with Trizol Reagent (Invitrogen, CA, USA) in accordance with the manufacturer's instructions. The cDNA species were synthesised with SuperScript II (Life Technologies) from $2 \mu \mathrm{g}$ of total RNA in a total volume of $20 \mu \mathrm{L}$ with an oligo (dT) primer. The cDNA reactions were performed for 1 hour at $42^{\circ} \mathrm{C}$ and stopped by boiling for 5 minutes. The cDNA was used as a template for PCR with specific primers for TGF- $\beta 1$. A 210 -bp sequence of the $\beta$-actin mRNA was chosen as an internal standard RNA for PCRs. To ensure that we were working in conditions of nonsaturation for the PCR reaction, a cycle curve was first made for each gene, since this is a semiquantitative method. Two microlitres of the RT reaction mix were used for PCR in a total volume of $25 \mu \mathrm{l}$ using the concentration of $0.5 \mu \mathrm{M}$ of each primer indicated below, together with $50 \mu \mathrm{M}$ of dNTP and $1 \mathrm{U}$ of Taq polymerase (Life Technologies) in the supplied reaction buffer. The primer of $\beta$-actin used in the reaction was diluted $(1: 20)$. The PCR cycling conditions were as follows: for TGF- $\beta 1$ : 1 minute at $94^{\circ} \mathrm{C}, 1$ minute at $64^{\circ} \mathrm{C}$, and 1 minute at $72^{\circ} \mathrm{C}$ (498-bp amplification product in 21 cycles); and for $\beta$-actin: 1 minute at $94^{\circ} \mathrm{C}, 1.5$ minute at $59.8^{\circ} \mathrm{C}$, and 1 minute $30 \mathrm{~s}$ at $72^{\circ} \mathrm{C}$ (210-bp amplification product in 34 cycles). All PCRs were carried out for an initial 3-minutes denaturation step at $94^{\circ} \mathrm{C}$ and a final 10 -minutes extension at $72^{\circ} \mathrm{C}$. The following set of primers were used: $5^{\prime}$ AAT ACG TCA GAC ATT CGG GAA GCA $3^{\prime}$ and $5^{\prime}$ GTC AAT GTA CAG CTG CCG TAC ACA $3^{\prime}$ for TGF- $\beta 1 ; 5^{\prime}$-TAT GCC AAC ACA GTG CTG TCT GG-3' and $5^{\prime}$-TAC TCC TGC TTC CTG ATC CAC AT- $3^{\prime}$ for $\beta$-actin. Oligonucleotides were obtained from Imprint Genetix (São Paulo, Brazil). Ten microlitres of the PCR product were analyzed on a $1.5 \%$ agarose gel. Using an Image Analysis System, the densitometric intensities of the TGF- $\beta$ and $\beta$-actin bands were converted to numeric values. The mRNA expression is expressed as mRNA of the gene of the interest, and the mRNA $/ \beta$-actin ratio is expressed as percentage.

2.6. Statistical Analysis. The data obtained are presented as mean \pm SD of at least three independent experiments and are expressed in percentage in relation to control. The number of experiments $(n)$ refers to the number of different cell extractions and each experiment was performed in triplicate. Data were analyzed using one-way analysis of variance, followed by Tukey's post hoc test, and values of $P<.05$ were considered statistically significant.

\section{Results}

3.1. $T_{3}$ Increases TGF- $\beta 1$ Levels in Cardiomyocytes Cultures. We have previously demonstrated that $\mathrm{TH}$-induced cardiac hypertrophy was accompanied by elevated cardiac TGF$\beta 1$ protein expression [19]. In order to evaluate whether TH would be able to modulate directly TGF- $\beta 1$ in isolated cardiac cells, we analyzed its protein and gene expression in cardiomyocytes cultures and in cardiac fibroblasts cultures, using, respectively, western Blotting and RT-PCR analysis (Figure 1). The cardiac fibroblasts submitted to $T_{3}(10 \mathrm{nM})$ treatment for 24 hours did not present alteration on TGF$\beta 1$ protein and gene expression compared to control cells (Figures 1(a) and 1(c)). However, the cardiomyocytes treated with $\mathrm{T}_{3}(10 \mathrm{nM})$ for 24 hours demonstrated a significant increase on TGF- $\beta 1$ protein and gene expression $(P<.01)$ in relation to control cells (Figures $1(\mathrm{~b})$ and $1(\mathrm{~d})$ ).

These results demonstrate that $\mathrm{T}_{3}$ increases the TGF- $\beta 1$ protein and gene expression in cardiomyocytes cultures.

\section{2. $T_{3}$ Induces Cardiomyocyte Growth via AT1R and AT2R.} We have previously demonstrated that AT1R acts as key mediator in the TH-mediated cardiac hypertrophy in vivo [9] and in vitro [11]. In addition, the AT2R was also shown to participate in this cardiac hypertrophy model. To confirm the participation of AT1R and AT2R in $T_{3}$ induced cardiomyocyte hypertrophy, we analyzed the protein synthesis as an indicator of hypertrophy (Figure 2). To address these questions, the cells were treated with $\mathrm{T}_{3}$ $(10 \mathrm{nM}), \mathrm{T}_{3}$ plus Losartan $(1 \mu \mathrm{M})$, an AT1R blocker, or $\mathrm{T}_{3}$ plus PD123319 $(1 \mu \mathrm{M})$, an AT2R blocker. As expected, the cardiomyocytes treated with $\mathrm{T}_{3}$ for 24 hours presented a significant increase in protein synthesis $(P<.01)$ in relation to control cells. However, protein synthesis was significantly lower in the cardiomyocytes treated with $\mathrm{T}_{3}$ plus Losartan $(P<.01)$ than in those only treated with $\mathrm{T}_{3}$. Similar results were obtained from the cells treated with $\mathrm{T}_{3}$ plus PD123319, which demonstrated a significant reduction on protein synthesis $(P<.05)$ when compared to $\mathrm{T}_{3}-$ treated cells. However, the cardiomyocytes treated with $\mathrm{T}_{3}$ plus PD123319 presented a significant increase on protein synthesis $(P<.05)$ in relation to control cells.

These data confirm the hypertrophic effect exerted by $\mathrm{T}_{3}$ on cardiomyocytes, as well as the important contribution of $\mathrm{AT} 1 \mathrm{R}$ and AT2R in this process.

3.3. $T_{3}$ Increases TGF- $\beta 1$ in Cardiomyocytes Independent of $A T 1 R$ and $A T 2 R$. We have previously showed that THinduced cardiac hypertrophy in vivo is accompanied by increased cardiac TGF- $\beta 1$ levels, which is mediated by AT1R and AT2R [19]. To investigate whether the $\mathrm{T}_{3}$-induced increase on TGF- $\beta 1$ expression in cardiomyocytes cultures might be mediated by the local Ang II receptors, present in these cells, as well as the possible participation of the TGF$\beta 1$ to the trophic effects exerted by $\mathrm{T}_{3}$ on cardiomyocytes, 


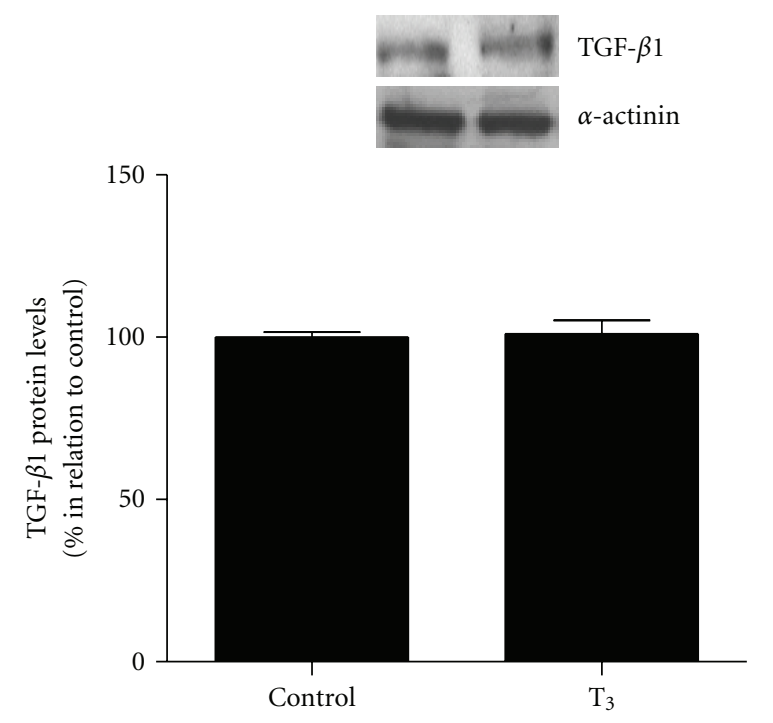

(a)

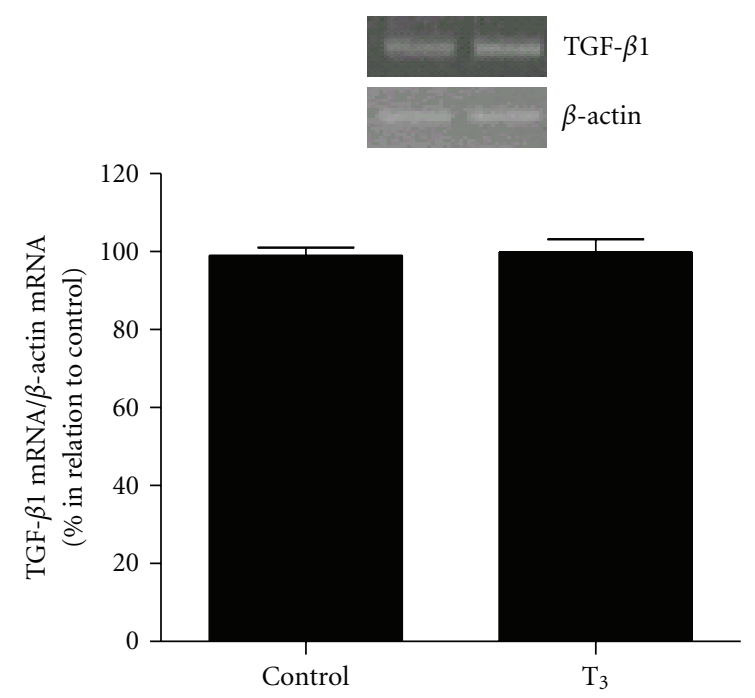

(c)

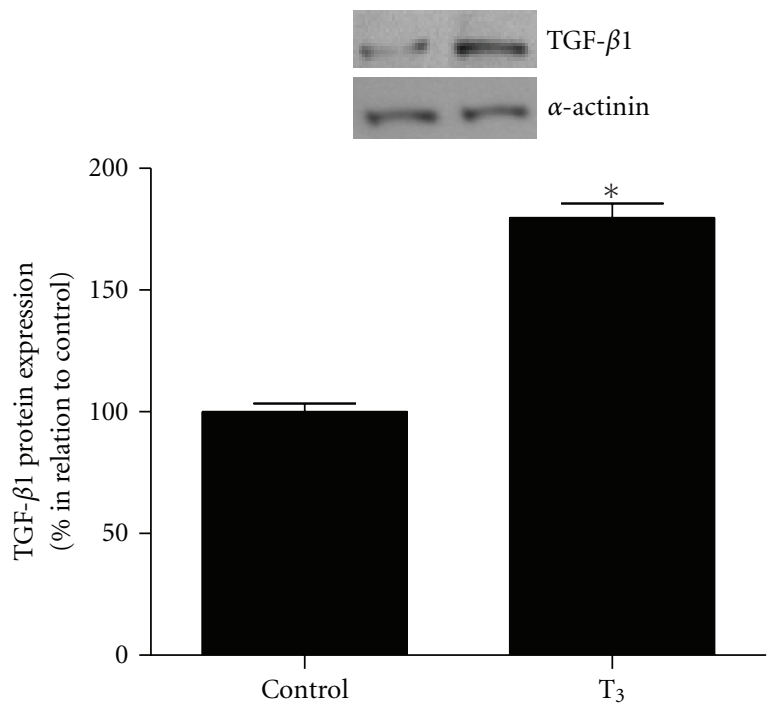

(b)

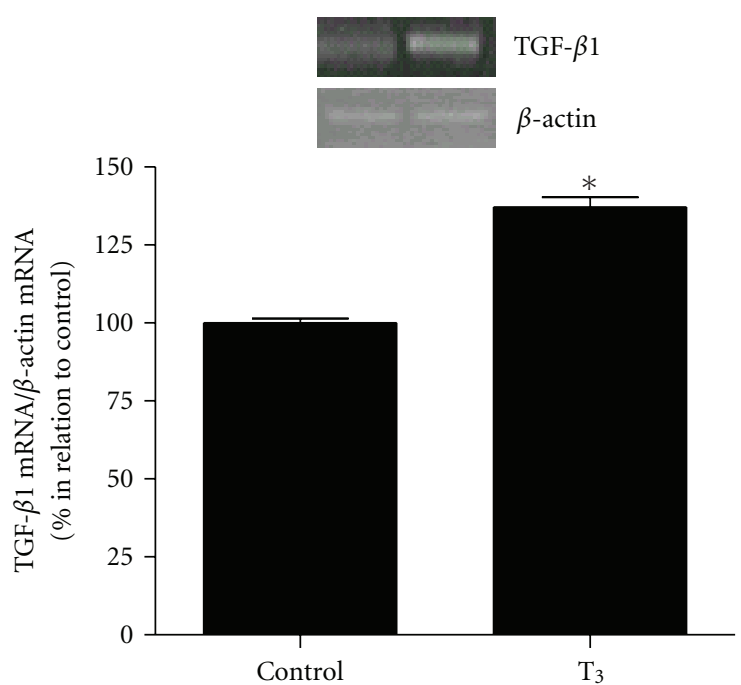

(d)

FIGURE 1: TGF- $\beta 1$ protein expression in cardiac fibroblasts (a) and cardiomyocytes cultures (b), evaluated by Western Blot. TGF- $\beta 1$ gene expression in cardiac fibroblasts (c) and cardiomyocytes cultures (d), evaluated by RT-PCR. The cells were treated for 24 hours with serumfree medium containing $10 \mathrm{nM}$ of $\mathrm{T}_{3}\left(\mathrm{~T}_{3}\right)$ or only serum-free medium in control cells. $\alpha$-actinin was used for normalization of TGF- $\beta 1$ protein expression and $\beta$-actin was used for normalization of TGF- $\beta 1$ gene expression. The values are expressed in percentage. ${ }^{*}$ versus control $P<.01(n=4)$.

we also evaluated the participation of AT1R and AT2R in the $\mathrm{T}_{3}$-induced increase on TGF- $\beta 1$ expression, using specific blockers (Figure 3 ). The cardiomyocytes cultures treated with $\mathrm{T}_{3}(10 \mathrm{nM})$ plus Losartan $(1 \mu \mathrm{M})$ demonstrated a significant increase in TGF- $\beta 1$ expression $(P<.01)$ in relation to control values. In the same way, the cardiomyocytes cultures treated with $\mathrm{T}_{3}(10 \mathrm{nM})$ plus PD123319 $(1 \mu \mathrm{M})$ presented higher TGF- $\beta 1$ expression $(P<.01)$ compared to control cells.

These results demonstrate that AT1R and AT2R do not mediate the $T_{3}$-induced increase in TGF- $\beta 1$ protein expression in cardiomyocytes cultures.

\section{Discussion}

Alterations on $\mathrm{TH}$ levels are able to influence cardiac function in different routes [22]. In this context, increased TH levels have been shown to promote cardiac hypertrophy [23] and Ang II receptors have a key role in mediating this process $[9,11]$. In addition, TH levels have also been shown to influence the cardiac Ang II receptors expression [24]. We have previously described that TH-induced cardiac hypertrophy is accompanied by elevated cardiac TGF- $\beta 1$ levels [19]. However, the exact mechanism by which TH increases the cardiac TGF- $\beta 1$ levels is unknown. Considering 


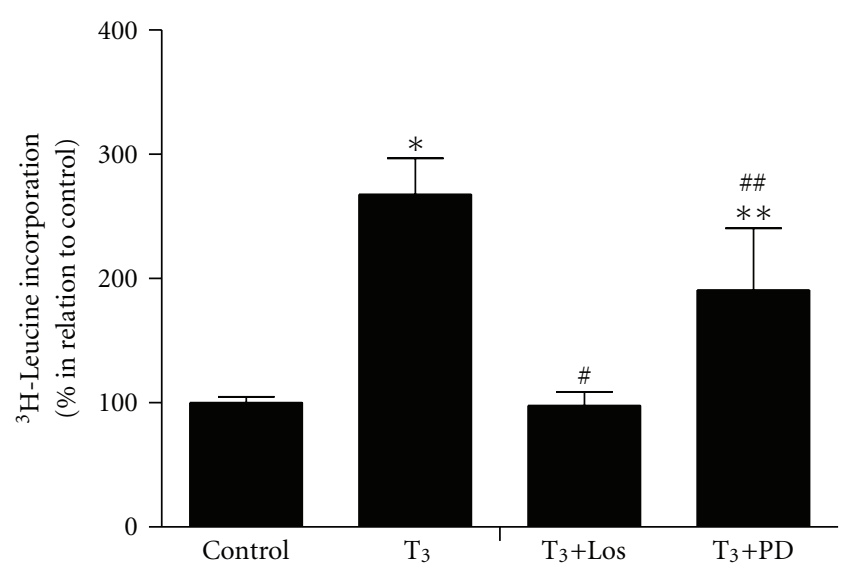

Figure 2: ${ }^{3} \mathrm{H}$-Leucine incorporation in cells treated with serumfree medium containing $10 \mathrm{nM}$ of $\mathrm{T}_{3}\left(\mathrm{~T}_{3}\right)$, as well as in cells treated with $10 \mathrm{nM}$ of $\mathrm{T}_{3}$ plus $1 \mu \mathrm{M}$ of Losartan (Los $+\mathrm{T}_{3}$ ), $10 \mathrm{nM}$ of $\mathrm{T}_{3}$ plus $1 \mu \mathrm{M}$ of $\mathrm{PD} 123319\left(\mathrm{PD}+\mathrm{T}_{3}\right)$ for 24 hours or only serum-free medium in control cells. Six hours before harvest, L $\left[3,4,5-{ }^{3} \mathrm{H}\right]$ leucine $(5 \mu \mathrm{Ci} / \mathrm{ml})$ was added to the culture medium to measure incorporation into newly synthesized protein. Results are expressed as percentages. ${ }^{*} P<.01$ versus control, ${ }^{* *} P<.05$ versus control, $\# P<.01$ versus $\mathrm{T}_{3}, \# \# P<.05$ versus $\mathrm{T}_{3}(n=3)$.

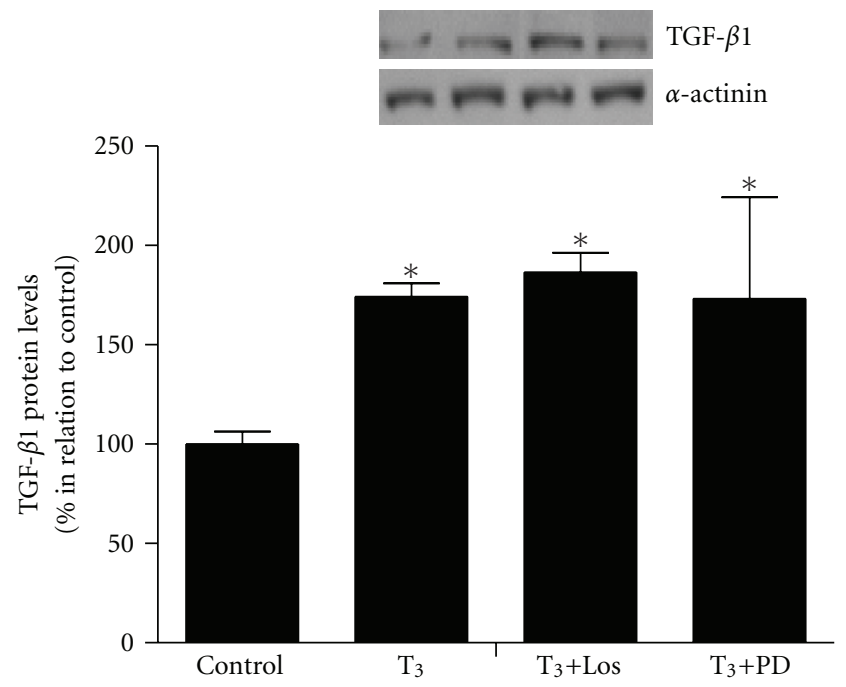

FIGURE 3: TGF- $\beta 1$ protein expression in cardiomyocytes cultures evaluated by Western Blot in cells treated with serum-free medium containing $10 \mathrm{nM}$ of $\mathrm{T}_{3}\left(\mathrm{~T}_{3}\right)$, as well as in cells treated with $10 \mathrm{nM}$ of $\mathrm{T}_{3}$ plus $1 \mu \mathrm{M}$ of Losartan (Los $+\mathrm{T}_{3}$ ), $10 \mathrm{nM}$ of $\mathrm{T}_{3}$ plus $1 \mu \mathrm{M}$ of PD123319 (PD $\left.+\mathrm{T}_{3}\right)$ for 24 hours or only serum-free medium in control cells. $\alpha$-actinin was used for normalization of TGF- $\beta 1$ expression. The values are expressed in percentage. ${ }^{*}$ versus control $P<.01(n=3)$.

this, the present was designed to evaluate whether TH would be able to modulate directly TGF- $\beta 1$ expression in isolated cardiac cells, as well as the possible contribution of AT1R and AT2R to this response. Our results demonstrated that $\mathrm{T}_{3}$ induces an increase in TGF- $\beta 1$ protein and gene expression in cardiomyocytes cultures but does not change the TGF- $\beta 1$ protein and gene expression in cardiac fibroblasts cultures.
In order to confirm the critical role exerted by the Ang II receptors to the development of $\mathrm{T}_{3}$-induced cardiomyocyte hypertrophy, we evaluated the protein synthesis of cardiomyocytes treated with $\mathrm{T}_{3}$ plus AT1R blocker or $\mathrm{T}_{3}$ plus AT2R blocker. Herein, we confirmed again that $\mathrm{T}_{3}$ stimulates cardiomyocyte hypertrophy via AT1R, since the use of a pharmacologic blocker of this receptor totally prevented the $\mathrm{T}_{3}$-induced cardiomyocyte hypertrophy. In addition, our results demonstrated that AT2R also contributes to the development of cardiomyocyte growth promoted by $\mathrm{T}_{3}$, since the use of a pharmacologic blocker of this receptor minimized the $\mathrm{T}_{3}$-induced hypertrophy. This result is in agreement with some recent studies of the literature, which have implicated the AT2R as a mediator of cardiac growth in vivo and in vitro $[13,14]$. However, the participation of AT1R to the $\mathrm{T}_{3}$-induced cardiomyocyte growth seems to be more accentuated than the participation of AT2R, suggesting that the AT1R is the main receptor responsible to mediate the trophic effects exerted by Ang II in these cells submitted to $\mathrm{T}_{3}$ treatment. This is an important question, which should be investigated.

We have previously demonstrated that the Ang II receptors mediate the increase in cardiac TGF- $\beta 1$ levels during the $\mathrm{TH}$-induced cardiac hypertrophy in vivo [19]. Considering that TH and RAS influence several hemodynamic factors, which could be responsible for the participation of the Ang II receptors in the $\mathrm{TH}$-induced increase on cardiac TGF- $\beta 1$ levels, in this study we evaluated whether the $\mathrm{T}_{3}$ induced increase in TGF- $\beta 1$ expression in cardiomyocytes cultures might be mediated by the local Ang II receptors present in these cells. Herein, we demonstrated that the increase induced by $\mathrm{T}_{3}$ on TGF- $\beta 1$ protein expression in cardiomyocytes cultures is not mediated by the Ang II receptors, since the use of AT1R and AT2R blockers did not attenuate the increase on TGF- $\beta 1$ protein expression promoted by $\mathrm{T}_{3}$ in these cells. These data suggest that the participation of the Ang II receptors mediating the increase on TGF- $\beta 1$ protein expression in the TH-induced cardiac hypertrophy in vivo probably is not dependent on the local AT1R and AT2R present in the cardiomyocytes. Moreover, considering that the AT1R and AT2R blockers prevented the increase in systolic blood pressure promoted by $\mathrm{TH}$ in vivo, as well as the increase in cardiac TGF- $\beta 1$ levels [19], it is plausible that the hemodynamic parameters altered in $\mathrm{TH}$-induced cardiac hypertrophy may be influencing the elevated TGF- $\beta 1$ levels in this model. In addition, several recent studies have emphasized the complexity of cardiac intracellular interactions where heart cells may be both source and target of signals such as cytokines and growth factors [25-27]. In this sense, the preservation of the cardiac architecture in vivo may be critical to the elevated cardiac levels of TGF- $\beta 1$ promoted by $\mathrm{TH}$ mediated by Ang II receptors.

Studies using cardiomyocytes cultures indicate that TGF$\beta 1$ stimulates protein synthesis [28]. In addition, the causal link between Ang II and TGF- $\beta 1$ in cardiac hypertrophy was recently demonstrated [29], since TGF- $\beta 1$ expression is increased by Ang II in cardiomyocyte [30]. In this sense, the myocardial induction of TGF- $\beta 1$ has been focus of 
particular interest in cardiac biology because this cytokine plays a crucial role in the transition from compensated to decompensated hypertrophy [31]. Taking this into account, it would be possible to suppose that part of the hypertrophic effect exerted by $\mathrm{T}_{3}$ on cardiomyocytes might be mediated by the higher TGF- $\beta 1$ protein expression. However, our data suggest that the trophic effects exerted by $\mathrm{T}_{3}$ on cardiomyocytes are not dependent of the higher TGF- $\beta 1$ levels, since the AT1R and AT2R blockers were able to attenuate the $\mathrm{T}_{3}$-induced cardiomyocyte hypertrophy but were not able to attenuate the increase on TGF- $\beta 1$ levels promoted by $\mathrm{T}_{3}$ in these cells. However, considering that the effects of TGF- $\beta 1$ are mediated by TGFR- $\beta 1$ and TGFR$\beta 2$ receptors, which are present in cardiomyocytes [32], the existence of the possible action of TH on TGF- $\beta 1$ receptors have to be considered. In this sense, it would be important to evaluate the $\mathrm{TH}$ effect on TGF- $\beta 1$ receptors in isolated cardiomyocytes. However, future studies will help in the elucidation of the exact role exerted by the elevated TGF- $\beta 1$ expression in $\mathrm{T}_{3}$-treated cardiomyocytes.

\section{Conclusions}

In summary, the data obtained in the present study demonstrate for the first time that $\mathrm{T}_{3}$ increases TGF- $\beta 1$ protein and gene expression in cardiomyocytes cultures. In addition, the results evidenced that the $\mathrm{TH}$-induced increase on TGF- $\beta 1$ levels in cardiomyocytes cultures is not dependent on local AT1R and AT2R present in these cells. Finally, these data suggest that the trophic effects exerted by $\mathrm{T}_{3}$ on cardiomyocytes are not dependent on the higher TGF$\beta 1$ levels, since the AT1R and AT2R blockers were able to attenuate the $\mathrm{T}_{3}$-induced cardiomyocyte hypertrophy but were not able to attenuate the increase on TGF- $\beta 1$ levels promoted by $\mathrm{T}_{3}$ in these cells.

\section{Acknowledgments}

This paper received financial support from the Fundação de Amparo à Pesquisa do Estado de São Paulo (FAPESP) and the Conselho Nacional de Desenvolvimento Cientifico e Tecnológico ( $\mathrm{CNPq}$, National Council for Scientific and Technological Development).

\section{References}

[1] S. Gupta, B. Das, and S. Sen, "Cardiac hypertrophy: mechanisms and therapeutic opportunities," Antioxidants and Redox Signaling, vol. 9, no. 6, pp. 623-652, 2007.

[2] P. Lijnen and V. Petrov, "Renin-angiotensin system, hypertrophy and gene expression in cardiac myocytes," Journal of Molecular and Cellular Cardiology, vol. 31, no. 5, pp. 949-970, 1999.

[3] M. Harada, H. Itoh, O. Nakagawa, et al., "Significance of ventricular myocytes and nonmyocytes interaction during cardiocyte hypertrophy: evidence for endothelin-1 as a paracrine hypertrophic factor from cardiac nonmyocytes," Circulation, vol. 96, no. 10, pp. 3737-3744, 1997.
[4] M. Harada, Y. Saito, K. Kuwahara, et al., "Interaction of myocytes and nonmyocytes is necessary for mechanical stretch to induce ANP/BNP production in cardiocyte culture," Journal of Cardiovascular Pharmacology, vol. 31, no. 1, pp. S357-S359, 1998.

[5] P. L. Puri, G. Natoli, M. L. Avantaggiati, C. Balsano, P. De Marzio, and M. Levrero, "The molecular basis of myocardial hypertrophy," Annali Italiani di Medicina Interna, vol. 9, no. 3, pp. 160-165, 1994.

[6] A. J. E. T. Van Wamel, C. Ruwhof, L. E. Van Der ValkKokshoorn, P. I. Schriern, and A. Van Der Laarse, "The role of angiotensin II, endothelin-1 and transforming growth factor- $\beta$ as autocrine/paracrine mediators of stretch-induced cardiomyocyte hypertrophy," Molecular and Cellular Biochemistry, vol. 218, no. 1-2, pp. 113-124, 2001.

[7] U. M. Schmidt-Ott and D. D. Ascheim, "Thyroid hormone and heart failure," Current Heart Failure Reports, vol. 3, no. 3, pp. 114-119, 2006.

[8] F. Liang, P. Webb, A. Marimuthu, S. Zhang, and D. G. Gardner, "Triiodothyronine increases brain natriuretic peptide (BNP) gene transcription and amplifies endothelin-dependent BNP gene transcription and hypertrophy in neonatal rat ventricular myocytes," Journal of Biological Chemistry, vol. 278, no. 17, pp. 15073-15083, 2003.

[9] L. W. Hu, L. A. Benvenuti, E. A. Liberti, M. S. Carneiro-Ramos, and M. L. M. Barreto-Chaves, "Thyroxine-induced cardiac hypertrophy: influence of adrenergic nervous system versus renin-angiotensin system on myocyte remodeling," American Journal of Physiology, vol. 285, no. 6, pp. R1473-R1480, 2003.

[10] C. Pantos, I. Paizis, I. Mourouzis, et al., "Blockade of angiotensin II type 1 receptor diminishes cardiac hypertrophy, but does not abolish thyroxin-induced preconditioning," Hormone and Metabolic Research, vol. 37, no. 8, pp. 500-504, 2005.

[11] G. P. Diniz, M. S. Carneiro-Ramos, and M. L. Barreto-Chaves, "Angiotensin type 1 receptor mediates thyroid hormoneinduced cardiomyocyte hypertrophy through the Akt/GSK$3 \beta / \mathrm{mTOR}$ signaling pathway," Basic Research in Cardiology, vol. 104, no. 6, pp. 653-667, 2009.

[12] J. Varagic and E. D. Frohlich, "Local cardiac reninangiotensin system: hypertension and cardiac failure," Journal of Molecular and Cellular Cardiology, vol. 34, no. 11, pp. 14351442, 2002.

[13] A. D'Amore, M. J. Black, and W. G. Thomas, “The angiotensin II type 2 receptor causes constitutive growth of cardiomyocytes and does not antagonize angiotensin II type 1 receptormediated hypertrophy," Hypertension, vol. 46, no. 6, pp. 13471354, 2005.

[14] T. Senbonmatsu, S. Ichihara, E. Price Jr., F. A. Gaffney, and T. Inagami, "Evidence for angiotensin II type 2 receptormediated cardiac myocyte enlargement during in vivo pressure overload," Journal of Clinical Investigation, vol. 106, no. 3, pp. R25-R29, 2000.

[15] J. N. Cohn, R. Ferrari, and N. Sharpe, "Cardiac remodelingconcepts and clinical implications: a consensus paper from an International Forum on Cardiac Remodeling," Journal of the American College of Cardiology, vol. 35, no. 3, pp. 569-582, 2000.

[16] J. M. Schnee and W. A. Hsueh, "Angiotensin II, adhesion, and cardiac fibrosis," Cardiovascular Research, vol. 46, no. 2, pp. 264-268, 2000.

[17] F. J. Villarreal and W. H. Dillmann, "Cardiac hypertrophyinduced changes in mRNA levels for TGF- $\beta 1$, fibronectin, and 
collagen," American Journal of Physiology, vol. 262, pp. H1861H1866, 1992.

[18] H. Lim and Y. Z. Zhu, "Role of transforming growth factor- $\beta$ in the progression of heart failure," Cellular and Molecular Life Sciences, vol. 63, no. 22, pp. 2584-2596, 2006.

[19] G. P. Diniz, M. S. Carneiro-Ramos, and M. L. M. BarretoChaves, "Angiotensin type 1 (AT1) and type 2 (AT2) receptors mediate the increase in TGF- $\beta 1$ in thyroid hormone-induced cardiac hypertrophy," Pflügers Archiv European Journal of Physiology, vol. 454, no. 1, pp. 75-81, 2007.

[20] M. L. M. Barreto-Chaves, A. Heimann, and J. E. Krieger, "Stimulatory effect of dexamethasone on angiotensinconverting enzyme in neonatal rat cardiac myocytes," Brazilian Journal of Medical and Biological Research, vol. 33, no. 6, pp. 661-664, 2000.

[21] A. Kenessey and K. Ojamaa, "Thyroid hormone stimulates protein synthesis in the cardiomyocyte by activating the AktmTOR and p70S6K pathways," Journal of Biological Chemistry, vol. 281, no. 30, pp. 20666-20672, 2006.

[22] G. J. Kahaly and W. H. Dillmann, "Thyroid hormone action in the heart," Endocrine Reviews, vol. 26, no. 5, pp. 704-728, 2005.

[23] B. M. Fadel, S. Ellahham, M. D. Ringel, J. Lindsay Jr., L. Wartofsky, and K. D. Burman, "Hyperthyroid heart disease," Clinical Cardiology, vol. 23, no. 6, pp. 402-408, 2000.

[24] M. S. Carneiro-Ramos, G. P. Diniz, J. Almeida, et al., "Cardiac angiotensin II type I and type II receptors are increased in rats submitted to experimental hypothyroidism," Journal of Physiology, vol. 583, no. 1, pp. 213-223, 2007.

[25] S. Fredj, J. Bescond, C. Louault, and D. Potreau, "Interactions between cardiac cells enhance cardiomyocyte hypertrophy and increase fibroblast proliferation," Journal of Cellular Physiology, vol. 202, no. 3, pp. 891-899, 2005.

[26] S. Fredj, J. Bescond, C. Louault, A. Delwail, J.-C. Lecron, and D. Potreau, "Role of interleukin-6 in cardiomyocyte/cardiac fibroblast interactions during myocyte hypertrophy and fibroblast proliferation," Journal of Cellular Physiology, vol. 204, no. 2, pp. 428-436, 2005.

[27] M. L. M. Barreto-Chaves, I. Aneas, and J. E. Krieger, "Glucocorticoid regulation of angiotensin-converting enzyme in primary culture of adult cardiac fibroblasts," American Journal of Physiology, vol. 280, no. 1, pp. R25-R32, 2001.

[28] J. R. Florini and D. Z. Ewton, "Actions of anabolic hormones and growth factors on cultured neonatal heart cells," Growth Regulation, vol. 5, no. 1, pp. 28-35, 1995.

[29] J. Schultz Jel, S. A. Witt, B. J. Glascock, et al., "TGF-beta1 mediates the hypertrophic cardiomyocyte growth induced by angiotensin II," Journal of Clinical Investigation, vol. 109, pp. 787-796, 2002.

[30] M. O. Gray, C. S. Long, J. E. Kalinyak, H.-T. Li, and J. S. Karliner, "Angiotensin II stimulates cardiac myocyte hypertrophy via paracrine release of TGF- $\beta 1$ and endothelin1 from fibroblasts," Cardiovascular Research, vol. 40, no. 2, pp. 352-363, 1998.

[31] S. Wenzel, K. Schorr, H. Degenhardt, et al., "TGF- $\beta(1)$ downregulates PTHrP in coronary endothelial cells," Journal of Molecular and Cellular Cardiology, vol. 33, no. 6, pp. 11811190, 2001.

[32] T. Brand and M. D. Schneider, "Inactive type II and type I receptors for TGF $\beta$ are dominant inhibitors of TGF $\beta$ dependent transcription," Journal of Biological Chemistry, vol. 270, no. 14, pp. 8274-8284, 1995. 


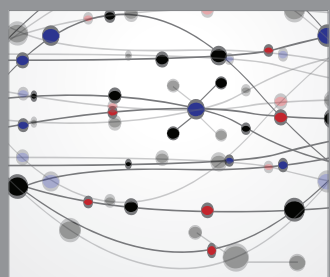

The Scientific World Journal
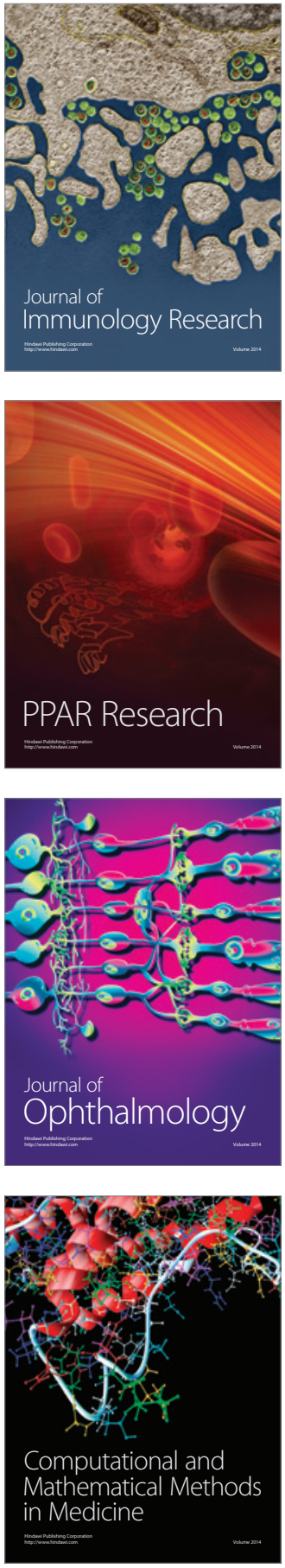

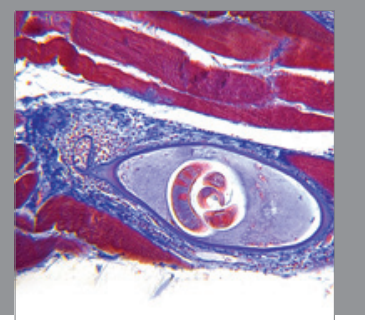

Gastroenterology

Research and Practice
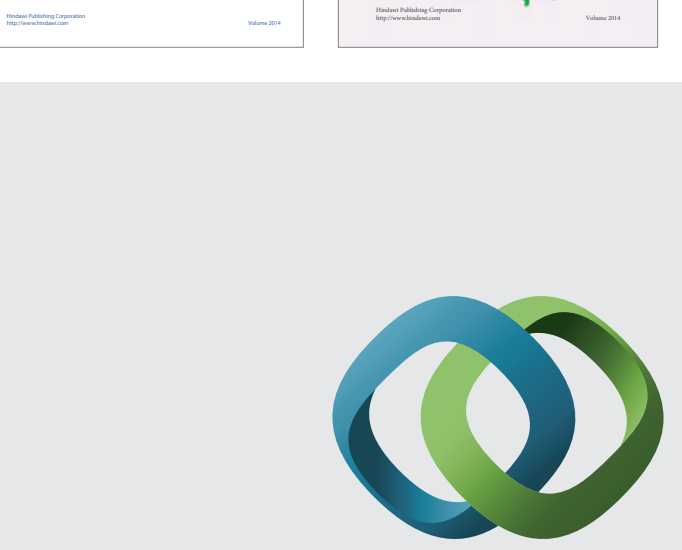

\section{Hindawi}

Submit your manuscripts at

http://www.hindawi.com
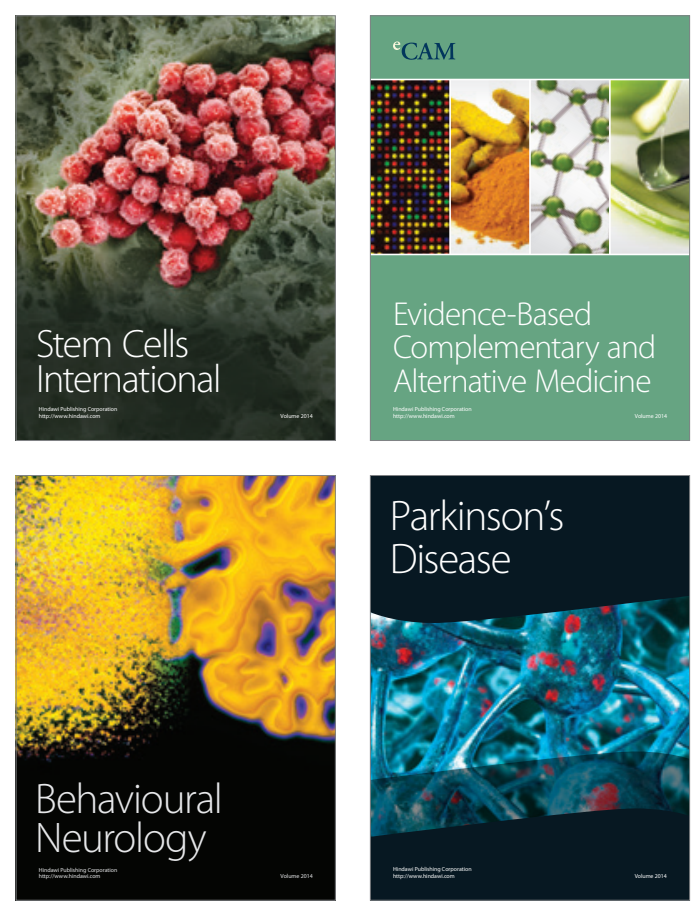

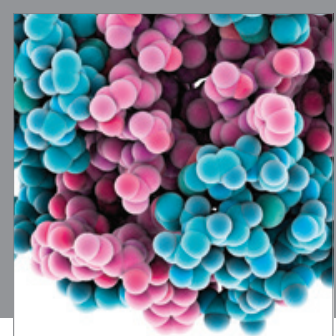

Journal of
Diabetes Research

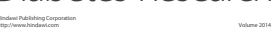

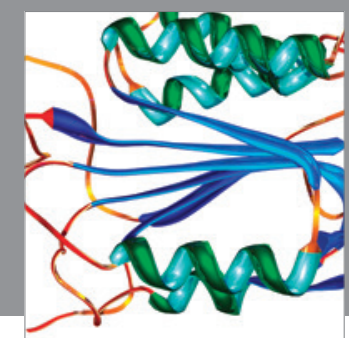

Disease Markers
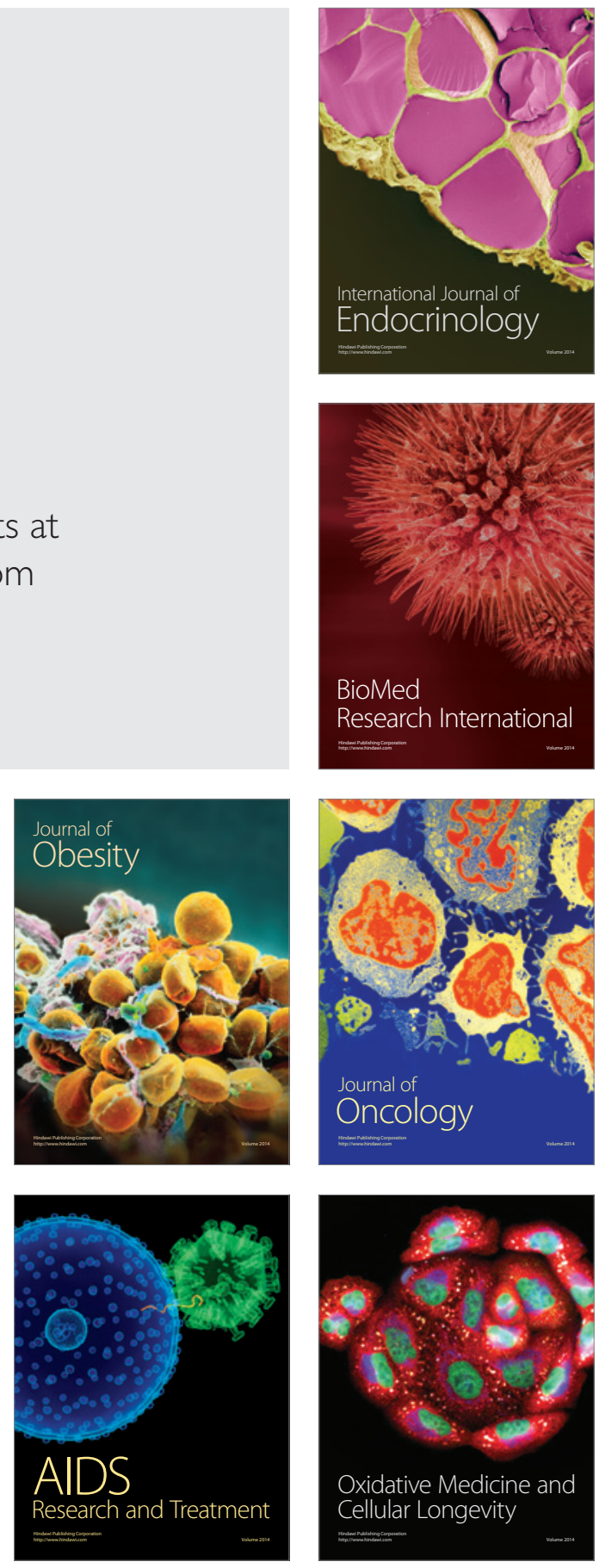